\title{
nombalina
}

(8)

\section{A genética em Pediatria}

Autor(es): $\quad$ Saraiva, Jorge

Publicado por: Imprensa da Universidade de Coimbra

URL

persistente: URI:http://hdl.handle.net/10316.2/43107

DOI: $\quad$ DOl:https://doi.org/10.14195/978-989-26-1300-0_6

Accessed : $\quad$ 26-Apr-2023 16:28:51

A navegação consulta e descarregamento dos títulos inseridos nas Bibliotecas Digitais UC Digitalis, UC Pombalina e UC Impactum, pressupõem a aceitação plena e sem reservas dos Termos e Condições de Uso destas Bibliotecas Digitais, disponíveis em https://digitalis.uc.pt/pt-pt/termos.

Conforme exposto nos referidos Termos e Condições de Uso, o descarregamento de títulos de acesso restrito requer uma licença válida de autorização devendo o utilizador aceder ao(s) documento(s) a partir de um endereço de IP da instituição detentora da supramencionada licença.

Ao utilizador é apenas permitido o descarregamento para uso pessoal, pelo que o emprego do(s) título(s) descarregado(s) para outro fim, designadamente comercial, carece de autorização do respetivo autor ou editor da obra.

Na medida em que todas as obras da UC Digitalis se encontram protegidas pelo Código do Direito de Autor e Direitos Conexos e demais legislação aplicável, toda a cópia, parcial ou total, deste documento, nos casos em que é legalmente admitida, deverá conter ou fazer-se acompanhar por este aviso.

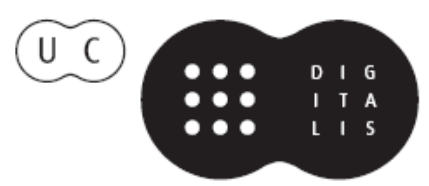


Capítulo 6.

A genética em Pediatria

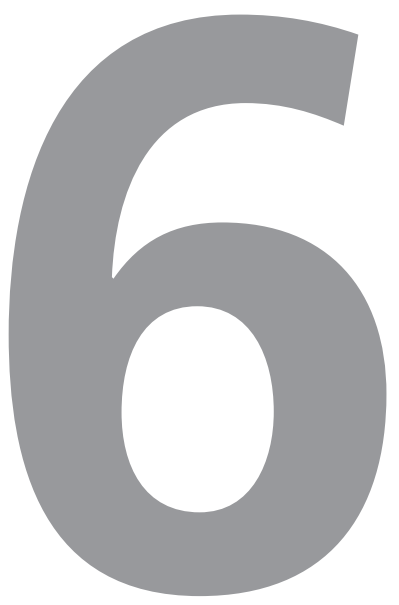

\section{Jorge Saraiva}




\subsection{CONTEXTO}

A grande maioria das doenças tem uma hereditabilidade significativa. Neste contexto é adequado em primeiro lugar recordar as diferentes características químicas da informação genética e a metodologia laboratorial disponível para a sua avaliação, depois estabelecer um limite entre o determinismo genético das doenças frequentes (quase todas) e das doenças raras (da grande maioria), estas últimas geralmente com diagnóstico em idade pediátrica, para finalmente consolidar a importância para os doentes e famílias de um diagnóstico precoce, em particular no caso das doenças raras.

\subsection{DESCRIÇÃO DO TEMA}

\section{A transmissão intergeracional}

de informação molecular

Os gâmetas participam na constituição do zigoto com vários tipos de moléculas suscetíveis de transmitir informação, nomeadamente proteínas e ácidos nucleicos. O modelo que resume toda a informação transmitida aos cromossomas e aos genes é uma visão redutora. Quer as proteínas, nomeadamente as histonas, constituintes dos cromossomas, quer os RNAs ou a presença ou ausência de metilação da sequência de bases do DNA podem ter um papel determinante no futuro funcionamento celular. Acresce que estes componentes da química celular são muito mais suscetíveis de modulação pelo comportamento dos pais e avós, evidentemente anteriores à produção do gâmeta no caso da linha patrilinear e do nascimento no caso da linha matrilinear. Nesta área foram identificadas diferenças em função não apenas do sexo do indivíduo (masculino ou feminino) mas também do sexo do progenitor (mãe ou pai, avó ou avô paterno ou materno).

Os testes genéticos disponíveis permitem avaliar variações quantitativas, do número ou das dimensões dos cromossomas, à escala microscópica ou submicroscópica, ou qualitativas, da sequência de bases ou da presença ou ausência de metilação de um gene.

A seleção do teste e a interpretação dos resultados exige um conhecimento geral da sua utilidade e limites:

O cariótipo permite identificar alterações cromossómicas numéricas e estruturais, tem um poder de resolução de referência de quatro Mb (a maior limitação) e é o único teste genético disponível em contexto assistencial que permite identificar alterações estruturais equilibradas (situação em que continua a ser insubstituível sendo por isso o meio complementar de diagnóstico genético de primeira linha para o estudo de casais com infertilidade; também é o melhor teste para confirmar a natureza da alteração identificada por outro método, por exemplo se uma trissomia 21 é livre ou tem origem numa translocação robertsoniana). Pode ser complementado com estudos de hibridação com sondas específicas situação em que a sua aplicação se alarga aos núcleos interfásicos cuja principal vantagem é o maior poder de resolução e o maior inconveniente fornecerem apenas informações relativamente à região selecionada para avaliação. 
A sequenciação de Sanger de um gene específico é realizada na prática por um número variável de reações de sequenciação, variável em função do número de exões e das suas dimensões. As regiões sequenciadas são os exões e as regiões intrónicas adjacentes. Continua a ser o método de referência para a determinação da ordenação das bases púricas e pirimídicas de qualquer região genómica e tem como principal inconveniente não fornecer qualquer informação sobre outros genes ou regiões reguladoras ou intrónicas afastadas dos exões.

Na transição entre os dois métodos convencionais anteriormente enumerados e as tecnologias inovadoras que a seguir descreveremos existem disponíveis para aplicabilidade em contexto clínico dois métodos utilizados atualmente com alguma frequência. Ambos utilizam metodologia molecular mas um avalia o número de cópias de regiões do genoma (Multiplex Ligation-dependent Probe Amplification-MLPA) identificando a presença de deleções ou duplicações das regiões cromossómicas selecionadas para avaliação e o outro detecta simultaneamente a presença ou ausência de centenas de variações de sequência patogénicas diferentes em um ou vários genes potencialmente responsáveis por um fenótipo (CHIP) - atualmente disponível comercialmente para surdez neurossensorial pré-lingual e miocardiopatias hipertróficas, por exemplo. Nos dois casos a vantagem é a determinação da presença ou ausência de alterações comprovadamente patogénicas e responsáveis pelos quadros clínicos referidos mas com o inconveniente de não facultarem qualquer informação sobre outras regiões genómicas (MLPA) ou outras mutações nos mesmos ou em outros genes (CHIP).

As plataformas de array existentes utilizam metodologias distintas e têm um poder de resolução maior ou menor. Em qualquer dos casos permitem identificar deleções ou duplicações de muito pequenas dimensões (sendo que este parâmetro é variável com o teste utilizado). Adicionalmente há que tomar em consideração se têm maior poder de resolução para regiões comprovadamente patogénicas ou não e se a metodologia permite identificar adicionalmente regiões de homozigotia (sugerindo a presença de uma doença de hereditariedade autossómica recessiva por presença em homozigotia de uma mutação herdada de um ascendente comum num gene com locus nessa região), presumível isodissomia uniparental (presença de duas cópias de uma região genómica com origem num único cromossoma de apenas um dos pais) ou avaliar

\section{a consanguinidade dos pais.}

\section{As técnicas de sequenciação de nova} geração (NGS) permitem obter a baixo custo e em curto espaço de tempo a informação relativa a todos os exões (sequenciação exómica) ou mesmo todo o genoma (sequenciação genómica). Atualmente a maior acessibilidade ocorre para testes genéticos que incluem a avaliação genómica de tendencialmente todos os genes possivelmente responsáveis por um fenótipo (painéis de genes). Independentemente das plataformas utilizadas e do grau de cobertura de todas as regiões do exoma ou do genoma a confirmação da presença 
das variações de sequência requer ainda hoje o recurso à metodologia de Sanger. No entanto existe um tipo de mutação (a expansão do número de tripletos) que não é identificado por estes métodos.

Em ambos os casos (array e NGS) a informação obtida abrange todo o genoma, apenas com as limitações já anteriormente referidas. A maior delas em ambos os métodos reside na frequente dificuldade de interpretação, nomeadamente quando a alteração identificada não está classificada como uma variante do normal ou uma mutação confirmada. É necessário garantir que cada uma das variações identificadas nestas circunstâncias é adequadamente analisada utilizando toda a informação disponível em bases de dados específicas, na família (relacionando a sua presença ou ausência com o fenótipo de cada indivíduo) em modelos que prevêm in silico a proteína produzida pelo gene com a presença da alteração em avaliação ou, quando existem recursos para tal, em modelos celulares ou animais.

Adicionalmente é obrigatório acautelar desde o início a forma como a informação obtida é (ou não é) transmitida. Uma vez que se trata de metodologias que avaliam globalmente o genoma, independentemente do contexto clínico, é necessário estabelecer um consenso prévio sobre os procedimentos a adotar quanto a alterações patogénicas identificadas mas não relacionadas com a indicação médica para a realização do teste. Pode ser obtida informação com utilidade clínica presente ou futura, em contexto individual ou reprodutivo que podemos classificar da seguinte forma: identificação de alteração patogénica suscetível de melhoria do prognóstico se terapêutica específica for iniciada antes do início da sintomatologia, em idade pediátrica ou apenas após a maioridade; identificação de alteração patogénica sem terapêutica específica estabelecida com início de sintomatologia em idade pediátrica ou apenas após a maioridade; identificação de alteração que apenas aumenta ou diminui a probabilidade de manifestação de determinada doença; identificação da probabilidade de uma determinada terapêutica farmacológica ser ou não eficaz e vir ou não a ter efeitos secundários graves, para uma doença presente ou ausente; identificação do risco de transmissão de uma doença hereditária a um filho. A necessidade de estabelecer previamente regras quanto à informação que será ou não transmitida, em que contexto e quando (nomeadamente quanto a informação obtida em testes realizados a menores mas apenas relevantes para a vida adulta) deve anteceder obrigatoriamente a realização deste tipo de testes genéticos.

\section{Determinismo genético}

de doenças frequentes

A hipertensão arterial, a diabetes mellitus, as dislipidémias, a asma, o cancro, a perturbação do espetro do autismo e muitas outras situações são problemas de saúde frequentes e heterogéneos quanto à etiologia. A perturbação do espetro do autismo tem uma frequência estimada de até um por cento e uma hereditabilidade de 50\%. Nalguns casos de autismo a hereditabilidade é de 100\%: a presença de uma variação de sequência patogénica, uma microdeleção ou uma microduplicação é suficiente para a manifestação do fenótipo; em muitos outros casos é a coexistência de várias das alterações referidas que determina a probabilidade maior ou menor da doença existir 
- e nalguns casos esta probabilidade é também modulada pelo sexo feminino ou masculino do indivíduo sendo regra geral a existência de um efeito protetor no sexo feminino. E na grande maioria a causa continua a ser desconhecida. Este modelo aplica-se com adaptações específicas a quase todas as doenças frequentes.

Alguns casos, uma minoria, são uma consequência quase obrigatória da presença de uma única variação de sequência génica patogénica, herdada de um dos progenitores ou de novo (5\% no caso das doenças oncológicas mais frequentes).

Noutras situações a variação de sequência génica é indiferente para a saúde do indivíduo exceto se exposto a um fator ambiental. A fenilcetonúria é o resultado da exposição a um aminoácido de um indivíduo com ausência de produção de uma enzima funcionante. Para além deste exemplo em que a doença está presente apenas mas sempre que se verificam as duas condições (o fator ambiental e o genético) muitos outros casos existem em que ambos interferem na probabilidade de manifestação da patologia: a doença celíaca exige a exposição ao glúten e a presença de um alelo específico do sistema de histocompatibilidade mas a presença de ambos não origina obrigatoriamente a presença da doença. O tabagismo é um fator de risco para o cancro do pulmão mas existe cancro do pulmão na sua ausência; e uma variação de sequência génica, indiferente para os não fumadores, determina que nos fumadores a probabilidade de ter cancro do pulmão seja de seis ou 12\%. Numa perspetiva populacional esta informação pode ser classificada como desnecessária, uma vez que a recomendação para a adoção de estilos de vida saudável, incluindo não fumar, tem um impacto global positivo. A estratificação genética da população em grupos de risco mais elevado e mais baixo é geralmente apresentado como uma oportunidade de, no primeiro, aumentar a motivação para a prevenção e oferecer o rastreio e o diagnóstico precoce.

Neste grupo de doenças a confirmação ou exclusão da presença de uma etiologia genética faz-se habitualmente em casos selecionados pela maior probabilidade de um resultado positivo. São considerados os fatores individuais e familiares que determinam a realização de testes genéticos e a sua escolha.

Assim é no caso da seleção de doentes com diabetes mellitus para realização dos testes moleculares de diabetes tipo - Maturity onset diabetes of the young (MODY). Ou a seleção dos casos de cancro da mama para testes moleculares nos genes BRCA1 e BRCA2. Evidentemente que haverá que tomar em consideração por um lado que existem outros genes que determinam uma maior suscetibilidade; e que quando se estabelece como critério de inclusão uma mulher que tem uma probabilidade igual ou superior a $10 \%$ de ter uma mutação patogénica num dos dois genes referidos estamos a excluir a sua realização em mulheres com uma alteração desse tipo apenas porque a probabilidade de ter um resultado positivo é inferior a 10\%. Nestes cenários a existência ou não de um limiar e o seu valor são o resultado da disponibilidade dos testes e, desejavelmente, da acessibilidade com equidade: enquanto não houver disponibilidade, por motivos tecnológicos, organizacionais ou económicos, para realizar o teste a todas as mulheres são selecionados os casos com maior probabilidade de ter um resultado positivo. 
Noutras situações a avaliação das vantagens e inconvenientes da utilização de testes genéticos resulta na recomendação atual de realizar alguns em determinados diagnósticos: está indicado realizar um Microarray-based comparative genomic hybridisation (array $\mathrm{CGH}$ ) e a determinação do número de tripletos do gene FMR1 a todos os indivíduos com défice intelectual de etiologia desconhecida, com taxas de resultados positivos respetivamente de 15 a $25 \%$ e de dois a quatro por cento. A sequenciação exómica total estabeleceria o diagnóstico etiológico em outros $25 \%$ dos casos, o que deve ser analisado em duas perspetivas complementares: o conhecimento atual permite identificar uma causa genética do défice intelectual em 50\% dos casos; mas metade destes não terá acesso à metodologia laboratorial enquanto não for confirmada a sua utilidade clínica, nomeadamente com a sensibilidade e a interpretação dos resultados, e, o que se antecipa mais problemático, disponibilizar os recursos organizacionais e económicos necessários.

\section{Determinismo genético}

de doenças raras

As doenças raras são todas as que têm uma prevalência inferior a um em 2.000 (5/10.000). Apesar de cada uma delas, por definição, ser incomum são muito numerosas, mais de 8.000 , e em $80 \%$ a etiologia é genética. Epidemiologicamente pode assim afirmar-se que seis a oito por cento da população terá uma doença rara durante a sua vida. Em Portugal cada médico da especialidade de medicina geral e familiar poderá ter na sua lista de utentes mais de uma centena de pessoas com uma doença rara. Este grupo de pessoas recorre com mais frequência a cuidados de saúde, em particular dos diferenciados, pelo que está sobrerepresentado nas consultas e internamentos hospitalares. As doenças raras podem afetar qualquer órgão ou sistema, algumas delas podem ser diagnosticadas in uteru e são maioritariamente hereditárias pelo que suscitam a intervenção de todas as especialidades médicas e cirúrgicas no seu diagnóstico e terapêutica. Por estes motivos é uma falácia atribuir a responsabilidade do diagnóstico e terapêutica de todas as doenças raras a alguns centros de referência.

Em idade pediátrica, período da vida em que ocorrem as primeiras manifestações das doenças raras, um terço dos doentes internados tem uma doença rara e estes internamentos são mais prolongados e têm uma mortalidade quatro vezes superior.

Em Portugal a legislação e normas em vigor estabelecem que em todos os casos em que se efetue um teste genético o médico deve realizar aconselhamento genético antes e depois da sua realização; e que sempre que se confirme o diagnóstico de uma doença genética as famílias devem ser referenciadas à especialidade de genética médica.

Estes princípios aplicam-se aos testes genéticos de diagnóstico e de farmacogenética. No caso da sua realização em menores é exigido um consentimento escrito assinado por um dos pais ou tutores. Os testes genéticos de heterozigotia, pré-sintomáticos e de suscetibilidade e ainda em contexto de diagnóstico prénatal e pré-implantação exigem ainda o cumprimento de determinações específicas quanto à especialidade habilitada a realizar o pedido e/ou a forma de arquivo da informação obtida. Existem ainda restrições específicas aplicáveis às pessoas sem autonomia. 
A importância de um diagnóstico precoce

Abordamos aqui as repercussões para o doente e para a família de um diagnóstico com identificação precisa da doença, e da etiologia sempre que conhecida, o mínimo de tempo possível após o início das manifestações clínicas. Não se trata pois de rastreios, ocasionalmente referidos com esta designação, e que aqui serão discutidos em outros capítulos (rastreio neo-natal de hipotiroidismo, doenças hereditárias do metabolismo e fibrose quística; rastreios neo-natais de surdez, de cardiopatias congénitas, de displasia congénita da anca, de hipertensão arterial e de dislipidémias).

Uma criança (ou adulto) beneficia de um diagnóstico etiológico precoce por passar a usufruir de um programa de promoção e vigilância da saúde específico que contempla acompanhamento apropriado, vigilância das complicações associadas, planeamento educativo mas também da abstenção de exames desnecessários. A família lucra com o acesso a informação adequada, acompanhamento, participação em grupos de apoio e aconselhamento genético.

Em concreto o crescimento deve ser acompanhado com curvas específicas para a doença (i.e. trissomia 21, acondroplasia ou síndrome de Marfan), os parâmetros do desenvolvimento psicomotor interpretados de acordo com o habitual para cada diagnóstico, a realização de meios complementares de diagnóstico (mantendo o exemplo da trissomia 21: o hipotiroidismo e a doença celíaca) e de avaliações específicas escalonadas (ainda para o mesmo exemplo a acuidade visual e auditiva) em função da frequência e idade da sua ocorrência bem assim como os cuidados antecipatórios, nomeadamente quanto a atividade física, perfis comportamentais e integração na vida adulta.

\subsection{FACTOS A RETER}

A avaliação do determinismo genético das doenças frequentes não tem atualmente utilidade clínica;

Os futuros médicos de todas as especialidades têm de conhecer a epidemiologia das doenças genéticas e intervir no diagnóstico, na terapêutica e no acompanhamento das pessoas com doenças raras.

Os futuros médicos devem executar a referenciação correta dos doentes e familiares.

Os futuros médicos devem conhecer os princípios gerais, vantagens e limitações dos rastreios e das diferentes metodologias de testes genéticos e interpretar os resultados.

Os futuros médicos devem aplicar os princípios gerais do aconselhamento genético ao abordar com os doentes e as famílias os resultados dos testes genéticos.

Os futuros médicos devem implementar os planos de promoção e vigilância da saúde de pessoas com doenças raras.

Os futuros médicos devem defender os direitos das pessoas com doenças raras e das suas famílias.

\section{Leitura complementar}

Decretro-Lei $n^{\circ}$ 131/2014 de 29 de agosto

Lei n 12/2005 Informação genética pessoal e informação de saúde

Despacho $n^{\circ}$ 2129-B/2015 de 26 de fevereiro Estratégia Integrada para as Doenças Raras 2015-2020. 